LETTERS

\title{
Treatment of resistant rheumatoid arthritis by intra-articular infliximab injections: a pilot study
}

\author{
S N Nikas, T I Temekonidis, A K Zikou, M I Argyropoulou, S Efremidis, A A Drosos
}

Ann Rheum Dis 2004;63:102-103. doi: 10.1136/ard.2003.006981

$\mathrm{R}$

heumatoid arthritis (RA) is a chronic inflammatory disease which is characterised mainly by synovial inflammation and joint destruction, as well as extraarticular manifestations. ${ }^{1}$ Cytokines have a central role in the pathogenesis of this synovial inflammation. Tumour necrosis factor $\alpha(\mathrm{TNF} \alpha)$ is one of the dominant cytokines. Many studies have shown that TNF $\alpha$ is present in biologically significant amounts in RA synovial tissue and fluids, and the amount seems to parallel the extent of inflammation and bone erosion. ${ }^{23}$

Persistent inflamed monarthritis in patients with RA is difficult to treat. Usually it is treated with local patches, intraarticular injections of steroids, or even with chemical, radioactive, or surgical synovectomy. ${ }^{4}$ The introduction of anti-TNF $\alpha$ treatments, especially the infusion of infliximab, ${ }^{5}$ prompted us to investigate the effectiveness and safety of intra-articular injection of infliximab in patients with RA and resistant monarthritis.

\section{METHODS AND RESULTS}

Five patients who fulfilled the American College of Rheumatology criteria for RA were studied. ${ }^{6}$ All were receiving treatment with disease modifying antirheumatic drugs (DMARDs). They presented an active inflammatory monarthritis, resistant to local treatment with corticosteroids for a period of at least three months. Written informed consent was obtained from the patient, who were given intra-articular infliximab, $100 \mathrm{mg}$, in two consecutive injections at a 24 hour interval after local anaesthesia. The primary end point was to examine the efficacy and safety of intra-articular infliximab administration in patients with RA who had a partial response to DMARDs and exhibited signs and symptoms of persistent inflammation of one large joint. The current treatment was maintained during the study. The secondary end point was the comparison of magnetic resonance imaging (MRI) findings before and six weeks after infliximab administration. ${ }^{7}$ Patients with a history or presence of chronic infectious diseases, positive tuberculin skin test, or abnormal chest radiograph were excluded from the study.

Each patient had a complete physical and laboratory evaluation before and six weeks after treatment. The inflamed joint was examined and the following variables were evaluated: the degree of swelling and tenderness of the affected joint (mild $1+$, moderate $2+$, severe $3+$ ), the pain score (visual analogue scale $0-10 \mathrm{~cm}$ ), and the patient's and doctor's global assessment. In addition, a magnetic resonance (MR) examination of the inflamed joint was performed before and after treatment and the findings were read "blindly" and separately by two expert radiologists. The MR protocol consisted of sagittal short time inversion recovery scans and fat suppressed $T_{1}$ weighted sagittal, coronal, and axial scans before and after intra-venous contrast injection (Gd-DTPA). Intraarticular fluid collection and synovial thickening with enhancement were considered as findings of synovial inflammation.

Finally, acute phase reactants such as $\mathrm{C}$ reactive protein and erythrocyte sedimentation rate were evaluated in all patients.

Three female and two male patients with a mean (SD) age of 52.2 (8.5) years and mean (SD) disease duration of 11.3 (2.2) years were studied. Three had positive IgM rheumatoid factor. Four of the five patients responded well after the intra-articular injection of infliximab as evaluated by the reduction in the swelling and tenderness, by the decrease in the pain score, and by the improvement of laboratory variables (table 1). This clinical and laboratory improvement was associated with the improvement of MRI findings, which showed reduction of synovial fluid and of the enhancing inflammatory tissue (fig 1). One patient did not respond to intra-articular injection of infliximab and the MRI findings did not show any improvement. This patient had a synovitis flare in many joints and was treated successfully with intravenous

Table 1 Clinical and laboratory changes in patients with RA treated with intra-articular injections of infliximab

\begin{tabular}{|c|c|c|c|c|c|c|c|c|c|c|c|}
\hline \multirow[b]{2}{*}{ Variables } & \multicolumn{2}{|c|}{ Patient 1} & \multicolumn{2}{|c|}{ Patient 2} & \multicolumn{2}{|c|}{ Patient 3} & \multicolumn{2}{|c|}{ Patient 4} & \multicolumn{2}{|c|}{ Patient 5} & \multirow[b]{2}{*}{ p Value } \\
\hline & Before & After & Before & After & Before & After & Before & After & Before & After & \\
\hline Degree of swelling in the joint & 3 & 3 & 2 & 0 & 3 & 0 & 3 & 0 & 3 & 1 & 0.049 \\
\hline Degree of tenderness of the joint & 2 & 2 & 3 & 1 & 3 & 1 & 3 & 1 & 2 & 0 & 0.046 \\
\hline Pain score & 7.8 & 7.6 & 6.2 & 1.3 & 6.8 & 0.7 & 8.4 & 3.3 & 5.5 & 2.1 & 0.043 \\
\hline Patient's global assessment & 7.2 & 6.9 & 5.6 & 1.7 & 7.6 & 2.3 & 8,2 & 3.6 & 4.6 & 3.8 & $0.080^{*}$ \\
\hline Doctor's global assessment & 6.7 & 6.5 & 6.3 & 2.1 & 6.6 & 2.2 & 7.9 & 3.2 & 4.9 & 4.1 & 0.043 \\
\hline $\begin{array}{l}\text { Erythrocyte sedimentation rate } \\
(\mathrm{mm} / 1 \text { st h) }\end{array}$ & 60 & 58 & 41 & 24 & 75 & 13 & 28 & 20 & 46 & 30 & 0.043 \\
\hline $\mathrm{C}$ reactive protein $(\mathrm{mg} / \mathrm{l})$ & 15 & 18 & 14 & 1 & 81 & 2 & 8 & 0.5 & 8 & 1 & 0.050 \\
\hline Remission follow up (months) & No & 6 & & 6 & & 6 & & & 6 & & \\
\hline
\end{tabular}

For the statistical analysis Wilcoxon test for pairs was used; *non-statistical change. 

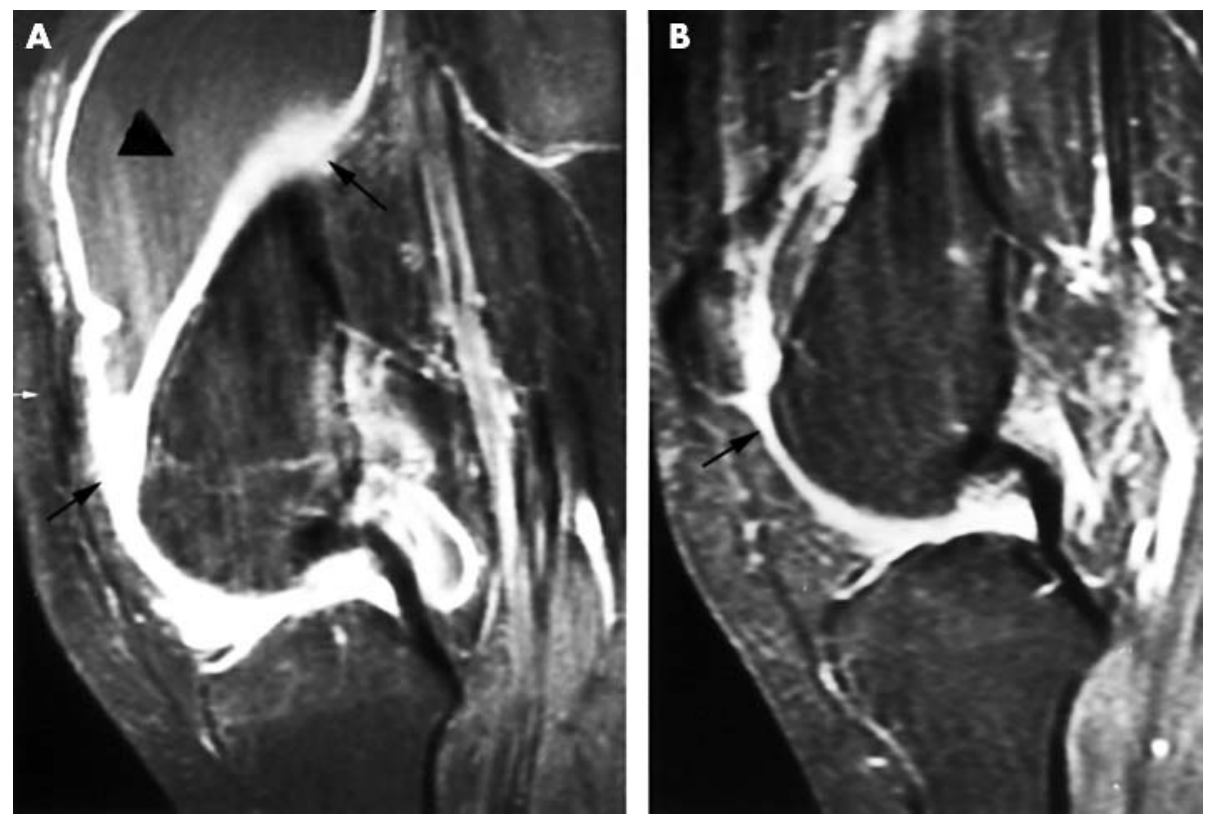

Figure 1 Contrast enhanced $\mathrm{T}_{1}$ weighted sagittal scan with fat suppression (A) demonstrating increased intra-articular fluid collection (arrowhead) and diffuse synovial thickening and enhancement (arrows); (B) showing disappearance of the intra-articular fluid and decrease of the enhancing inflammatory tissue (arrow) after intra-articular infliximab administration.

infusions of infliximab. No local or systemic adverse reactions were noted in our patients.

\section{DISCUSSION}

There is limited experience of intra-articular administration of infliximab in patients with RA. Dreher et al reported effectiveness with intra-articular infliximab in the local treatment of three patients with active RA, with an additional systemic effect. ${ }^{8}$ They noticed also a remarkable reduction of the daily cell count of the synovial fluid of one patient. Surprisingly, infliximab worked equally well in another patient with chondrocalcinosis, with immediate remission of clinical signs. Significant improvements were also seen by Lawless et al by injecting $1 \mathrm{mg}$ of infliximab dorsally into the left wrist of a patient with monarticular erosive arthritis following silastic wrist prosthesis. ${ }^{9}$ On the other hand, Kellner et al published successful treatment of sarcoiliitis in five patients with ankylosing spondylitis by intra-articular injection of $60 \mathrm{mg}$ infliximab. ${ }^{10}$

Intra-articular administration of infliximab seems to be effective and safe in patients with RA with resistant monarthritis. Large, placebo controlled studies are required to validate our results.

\section{Authors' affiliations}

S N Nikas, T I Temekonidis, A A Drosos, Division of Rheumatology, Department of Internal Medicine, University of loannina, loannina, Greece

A K Zikou, M I Argyropoulou, S Efremidis, Department of Radiology, Medical School, University of loannina, loannina, Greece
Correspondence to: Professor A A Drosos, Division of Rheumatology, Department of Internal Medicine, Medical School, University of loannina, 451 10, loannina, Greece; adrosos@cc.uoi.gr

Accepted 27 March 2003

\section{REFERENCES}

1 Gerli R, Lunardi C, Pitzalis C. Unmasking the anti-inflammatory cytokine response in rheumatoid synovitis. Rheumatology (Oxford) 2002;41:1341-5.

2 Brennan FM, Maini RN, Feldmann M. TNF alpha- $\alpha$ pivotal role in rheumatoid arthritis? Br J Rheumatol 1992;31:293-8.

3 Neidel J, Schulze M, Lindschau J. Association between degree of boneerosion and synovial fluid-levels of tumor necrosis factor alpha in the kneejoints of patients with rheumatoid arthritis. Inflamm Res 1995;44:217-21.

4 Roch-Bras F, Daures JP, Legouffe MC, Sany J, Combe B. Treatment of chronic knee synovitis with arthroscopic synovectomy: longterm results. J Rheumatol 2002;29:1171-5.

5 Maini R, St Clair EW, Breedveld F, Furst D, Kalden J, Weisman M, et al. Infliximab (chimeric anti-tumour necrosis factor alpha monoclonal antibody) versus placebo in rheumatoid arthritis patients receiving concomitant methotrexate: a randomised phase III trial. ATTRACT Study Group. Lancet 1999:354:1932-9

6 Arnett FC, Edworthy S, Bloch DA, McShane DJ, Fries JF, Cooper NS, et al. The ARA 1987 revised criteria for the classification of rheumatoid arthritis. Arthritis Rheum 1988;31:315-24.

7 Ostergaard M, Stoltenberg M, Lovgreen-Nielsen $P$, Volck B, Jensen $C H$, Lorenzen I. Magnetic resonance imaging-determined synovial membrane and joint effusion volumes in rheumatoid arthritis and osteoarthritis: comparison with the macroscopic and microscopic appearance of the synovium. Arthritis Rheum 1997;40:1856-67.

8 Dreher R, Flaig W, Leitzke D. Treatment of rheumatoid arthritis by intraarticular injections with TNF alpha blockers [abstract]. Arthritis Rheum 2001;44(suppl):42.

9 Lawless OJ, Pearson L, Malvern O. Monoarticular erosive arthritis following silastic wrist prosthesis: response to intrarticular infliximab [abstract]. Arthritis Rheum 2001;44(suppl):45.

10 Kellner H, Kroetz M, Schattenkirchner M, Kellner W. Successful therapy of sarcoiliitis in AS patients by intraarticular injection of infliximab [abstract]. Arthritis Rheum 2002;46(suppl):431. 


\section{Coeliac disease associated with systemic sclerosis}

\section{J A Gómez-Puerta, V Gil, R Cervera, R Miquel, S Jiménez, M Ramos-Casals, J Font}

Ann Rheum Dis 2004;63:104-105. doi: 10.1136/ard.2003.008888

S ystemic sclerosis (SSc) is a clinically heterogeneous disorder which affects the skin and internal organs such as the gastrointestinal tract, lungs, heart, and kidneys. Small bowel disease can present with a wide variety of symptoms, including intermittent bloating, abdominal cramps, chronic diarrhoea and, in a minority of patients, malabsorption. ${ }^{1}$ Coeliac disease (CD) is a malabsorptive disorder resulting from inflammatory injury to the mucosa of the small intestine after the ingestion of wheat gluten. As CD has an immunological basis, an association between CD and other autoimmune disorders, such as type 1 diabetes mellitus and autoimmune thyroiditis, is not uncommon. ${ }^{23}$ We describe here a patient with SSc and insulin dependent diabetes mellitus in whom a diagnosis of CD was made at the age of 49.

\section{CASE REPORT}

A 49 year old white woman with insulin dependent diabetes mellitus diagnosed in 1980, with weak positive anti-islet cell antibodies, recently attended our clinic. In 1995, she complained of Raynaud's phenomenon, ischaemic digital ulcers, sclerodactyly, and telangiectasia. A diagnosis of SSc with limited scleroderma was made supported by the presence of antinuclear $(1 / 160)$ and anticentromere antibodies. Lichen planus was diagnosed owing to hypochromic macular lesions on her thorax and arms. Associated sicca syndrome with anti SS-A/Ro antibodies was also diagnosed. Treatment with intravenous prostaglandins, calcium antagonists, and angiotensin converting enzyme inhibitors was started with good response.

Five years later, she presented with gastrointestinal symptoms, including dysphagia and oesophageal reflux, with barium studies that confirmed oesophageal hypomobility. She also presented with diarrhoea, with normal thyroid function, and with no evidence of infection. Symptomatic management was started, with transient improvement.

Three months later, she was admitted with a necrotic ischaemic digital episode of the second finger of her right hand complicated with osteomyelitis, and this was accompanied by an exacerbation of her abdominal symptoms. Laboratory findings showed malabsorption markers and positive IgA and IgG antigliadin and anti-endomysial antibodies. Jejune biopsy showed severe intestinal atrophy with a moderate lymphoplasmacytic infiltrate in the lamina propria and an increase of the intraepithelial lymphocytes

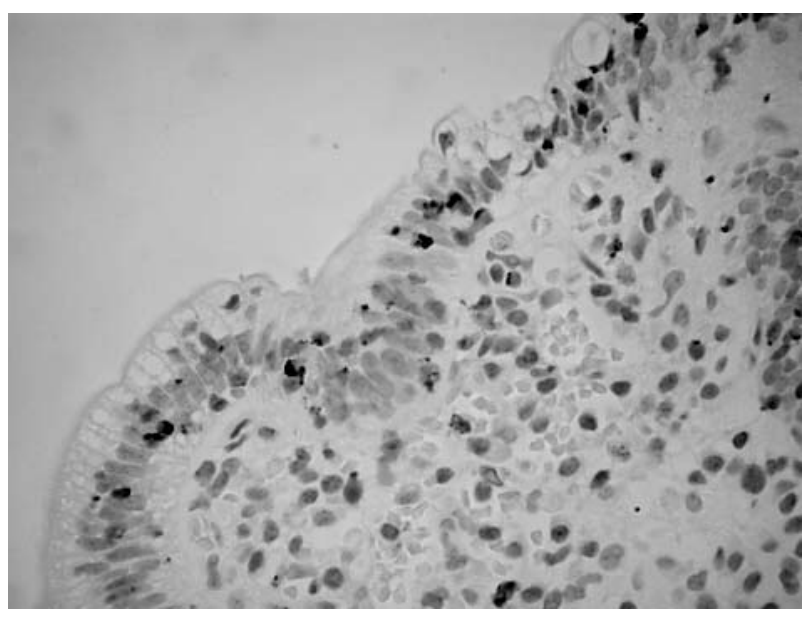

Figure 1 Granzyme B immunohistochemical staining. A high number of intraepithelial T lymphocytes showing cytoplasmic cytotoxic granules were identified (EnVision system, peroxidase, $\times 600$ ).

\begin{tabular}{|c|c|c|c|c|c|c|}
\hline \multirow[b]{2}{*}{ Characteristics } & \multicolumn{6}{|c|}{ Case No (ref) } \\
\hline & $\overline{1^{3}}$ & $2^{3}$ & $3^{5}$ & $4^{6}$ & $5^{6}$ & $6^{*}$ \\
\hline Age/sex & $21 / M$ & $54 / \mathrm{F}$ & $27 / F$ & $35 / F$ & $40 / M$ & $49 / \mathrm{F}$ \\
\hline Duration of SSc (years) & $<1$ & 9 & 1 & 3 & 13 & 8 \\
\hline Sicca symptoms & NR & NR & + & + & - & + \\
\hline Malabsorption markers & NR & NR & + & + & - & \\
\hline \multirow[t]{2}{*}{ Immunological profile } & NR & NR & $\begin{array}{l}\text { ANA+ } \\
(1 / 160)\end{array}$ & $\begin{array}{l}\text { ANA+ } \\
(1 / 1280)\end{array}$ & $\begin{array}{l}\text { ANA+ } \\
(1 / 640)\end{array}$ & $\begin{array}{l}\text { ANA+ } \\
(1 / 320)\end{array}$ \\
\hline & & & $\begin{array}{l}\text { RF+ } \\
\text { Thyroid abs }\end{array}$ & & $\mathrm{RF}_{+}$ & $\begin{array}{l}\text { RF+ } \\
\text { Centromere+ }\end{array}$ \\
\hline Antigliadin antibodies & NR & NR & + & + & NR & + \\
\hline Anti-endomysial antibodies & NR & NR & NR & NR & NR & + \\
\hline Intestinal biopsy with CD & + & + & + & + & + & + \\
\hline \multirow[t]{2}{*}{ Other autoimmune diseases } & - & - & $\mathrm{RA}, \mathrm{HT}$ & SS & - & DM \\
\hline & & & ITP, PA & & LP & \\
\hline \multicolumn{7}{|c|}{$\begin{array}{l}\mathrm{CD} \text {, coeliac disease; SSc, systemic sclerosis; RA, rheumatoid arthritis; } \mathrm{HT} \text {, Hashimoto's thyroiditis; ITP, idiopathi } \\
\text { thrombocytopenic purpura; PA, pernicious anaemia; DM, insulin dependent diabetes mellitus; LP, lichen planus; } \\
\text { ANA, antinuclear antibodies; RF, rheumatoid factor; NR, not reported. } \\
\text { *Present case. }\end{array}$} \\
\hline
\end{tabular}


(fig 1). A gluten-free diet was started, and her diarrhoea slowly improved.

\section{DISCUSSION}

A few publications have reported the coexistence of CD and SSc. $^{3-7}$ Zammit-Maempel et al reported on a 63 year old man with CD confirmed by jejunal biopsy associated with sclerodactyly, but without other clinical or serological features related to SSc. ${ }^{4}$ We found six well documented cases of patients with $\mathrm{CD}$ and SSc, including the current one (table 1). The mean age was 37.7 years (range $21-54$ ), with a mean duration of the SSc of 5.8 years (in one patient both diseases presented at the same time). Most of the patients were female (four women, two men) with limited scleroderma in five $(83 \%)$ of the six cases. Three of the patients had sicca symptoms, in one of them with a salivary gland biopsy that confirmed a diagnosis of Sjögren's syndrome.

The presence of Sjögren's syndrome or sicca symptoms in three of the six patients with CD and SSc deserves special comment. Iltanen et al found that five (15\%) of 34 patients with Sjögren's syndrome studied by an intestinal biopsy had concomitant $\mathrm{CD} .{ }^{8}$ Additionally, they suggested that a close association between these two disorders can be partly explained by a similar genetic involvement, specially the HLA DR3-DQ2 haplotype.

Our patient and the previous cases collected emphasise the importance of studying patients with SSc with chronic diarrhoea and malabsorption not only by antigliadin and anti-endomysial antibody determination but also, in some cases, by an intestinal biopsy, in order to clarify the source of the malabsorption, to obtain relief of symptoms, and to improve the prognosis of patients with SSc.

\section{Authors' affiliations \\ J A Gómez-Puerta, V Gil, R Cervera, S Jiménez, M Ramos-Casals, J Font, Department of Autoimmune Diseases, Hospital Clininc, Barcelona, Catalonia, Spain \\ R Miquel, Department of Pathology, Hospital Clínic, Barcelona, Catalonia, Spain}

Correspondence to: Dr R Cervera, Servei de Malalties Autoimmunes, Hospital Clínic, Villarroel 170, 08036-Barcelona, Catalonia, Spain; rcervera@clinic.ub.es

Accepted 27 March 2003

\section{REFERENCES}

1 Valentini G, Black C. Systemic sclerosis. Best Pract Res Clin Rheumatol 2002; 16:807-16

2 Farrell RJ, Kelly CP. Celiac sprue. N Engl J Med 2002;346:180-8.

3 Cooper T, Holmes GKT, Cooke WT. Coeliac disease and immunological disorders. BMJ 1978;i:537-9.

4 Zammit-Maempel I, Adamson AD, Halsey JP. Sclerodactyly complicating coeliac disease. Br J Rheumatol 1986;25:396-8.

5 Sheehan NJ, Stanton-King K. Polyautoimmunity in a young woman. Br J Rheumatol 1993;32:254-6.

6 Marguerie C, Kaye S, Mackworth-Young C, Walport MJ, Black C. Malabsorption caused by coeliac disease in patients who have scleroderma. Br J Rheumatol 1995;34:858-61.

7 Sheehan NJ, Stanton-King K. Co-existent coeliac disease and scleroderma. Br J Rheumatol 1996;35:807.

8 Iltanen S, Collin P, Korpela M, Holm K, Partanen J, Polvi A, et al. Celiac disease and markers of celiac disease latency in patients with primary Sjogren's syndrome. Am J Gastroenterol 1999;94:1042-6.

\section{Septic arthritis caused by Moraxella catarrhalis associated with infliximab treatment in a patient with undifferentiated spondarthritis}

\section{Olivieri, A Padula, L Armignacco, V Sabatella, M Mancino}

$\mathrm{T}$ umour necrosis factor $\alpha(\mathrm{TNF} \alpha)$ antagonists have been associated with reactivation of tuberculosis and development of other opportunistic infections. ${ }^{1-4}$ We have recently observed a case of septic arthritis caused by Moraxella (Branhamella) catarrhalis in a patient treated with infliximab that we describe briefly here.

\section{CASE REPORT}

The patient, a 45 year old man, was referred to us in September 1999 for evaluation of an eight year history of recurrent episodes of arthritis of the knees and elbows and of recurrent episodes of inflammatory swelling with pitting oedema over the dorsum of the hand. One year before the onset of arthritis he had undergone replacement surgery for an insufficient aortic valve. Physical examination disclosed swelling, effusion, and tenderness in the right knee, together with tenosynovitis of the left tibialis posterior and flexor digitorum longus. Spine movement was not limited and chest expansion was not restricted. Routine laboratory evaluation was normal and HLA typing was positive for B27. Radiographs of the knees showed only soft tissue swelling, and pelvis and spine radiographs were normal. The were no symptoms of gut disease, and ileocolonoscopy was not performed. Our diagnosis was undifferentiated spondarthritis (uSpA).
In the following months the patient developed severe recurrent episodes of peripheral arthritis, peripheral enthesitis, and tenosynovitis. At the beginning he was treated with steroid injections, non-steroidal anti-inflammatory drugs, and short courses of oral steroids. In the following months he was given sulfasalazine, cyclosporin $\mathrm{A}$, and methotrexate, with no improvement.

In May 2002, because of the severity of the clinical situation, we decided to treat the patient with infliximab, after obtaining his informed consent. He received the drug at a dose of $5 \mathrm{mg} / \mathrm{kg}$ by intravenous infusion at 0,2 , and 6 weeks. A fourth infusion was given two months after the third one. The improvement was only partial. The patient continued to have less severe peripheral manifestations of spondarthritis.

In October 2002, one month after the fourth infusion, he presented with a severe arthritis of the right knee. He denied any airway complaints. Arthrocentesis yielded $50 \mathrm{ml}$ of purulent fluid. Laboratory evaluation showed only an erythrocyte sedimentation rate (ESR) of $95 \mathrm{~mm} / \mathrm{lst} \mathrm{h}$ and a $\mathrm{C}$ reactive protein (CRP) level of $172 \mathrm{mg} / \mathrm{l}$ (normal $<5$ ). Earlier values were $2 \mathrm{~mm} / \mathrm{lst} \mathrm{h}$ and $0.7 \mathrm{mg} / \mathrm{l}$, respectively. Culture of the purulent synovial fluid grew Moraxella catarrhalis, and the blood culture was negative. The infection 
was cured with a two week course of antibiotic treatment with ciprofloxacin at a dosage of $1 \mathrm{~g} /$ day and teicoplanin at a dose of $200 \mathrm{mg} /$ day. Joint drainage was performed on two occasions. The ESR was $2 \mathrm{~mm} / \mathrm{lst} \mathrm{h}$ and CRP was $20.5 \mathrm{mg} / \mathrm{l}$ after the end of treatment.

\section{DISCUSSION}

Both the two TNF $\alpha$ antagonists, the mouse-human monoclonal IgGl monoclonal antibody infliximab and the $7 \mathrm{kDa}$ IgGl recombinant fusion protein etanercept, have been shown to be effective in ankylosing spondylitis and psoriatic arthritis. $^{56}$ Severe uSpA, unresponsive to sulfasalazine, is another possible indication for TNF $\alpha$ neutralising treatment. ${ }^{7}$ Our patient with severe uSpA unresponsive to sulfasalazine and methotrexate partially improved with infliximab. Unfortunately, the drug was stopped owing to the infection caused by Moraxella catarrhalis.

Opportunistic infections, including tuberculosis, ${ }^{1}$ aspergillosis, ${ }^{2}$ listeriosis, ${ }^{3}$ and histoplasmosis, ${ }^{4}$ are potential complications of treatment with TNF $\alpha$ blocking agents. Moraxella catarrhalis, a component of the normal bacterial flora of the upper airways and possibly the female genital tract, has recently emerged as a cause of different illnesses, including sinusitis, otitis media, conjunctivitis, laryngitis, bronchitis and pneumonia, and systemic infections in immunocompromised patients. ${ }^{8}$ There are also reports of septic arthritis due to Moraxella catarrhalis. ${ }^{10}$ Our patient developed Moraxella catarrhalis arthritis after the third infusion of infliximab. He was immunocompromised also because he had received immunosuppressive disease modifying treatment with methotrexate in the eight months before beginning the anti-TNF $\alpha$ blocking therapy.

In conclusion, we suggest that Moraxella catarrhalis should be included in the list of opportunistic organisms inducing infection associated with anti-TNF $\alpha$ blocking therapy.
Authors' affiliations

I Olivieri, A Padula, Rheumatology Department of Lucania, S Carlo Hospital, Potenza and Madonna delle Grazie Hospital, Matera, Italy L Armignacco, V Sabatella, Department of Infectious Diseases, San Carlo Hospital, Potenza, Italy

M Mancino, Microbiology Service, San Carlo Hospital, Potenza, Italy

Correspondence to: Dr I Olivieri, Rheumatology Department of Lucania, San Carlo Hospital, Contrada Macchia Romana, 85100 Potenza, Italy; ignazioolivieri@tiscalinet.it

Accepted 27 March 2003

\section{REFERENCES}

1 Keane J, Gershon S, Wise RP, Mirabile-Levens E, Kasznica J, Schwieterman WD, et al. Tubercolosis associated with infliximab, a tumor necrosis factor alpha-neutralizing agent. N Engl J Med 2002;346:1098-104.

2 Warris A, Bjorneklett A, Gustand P. Invasive pulmonary aspergillosis associated with infliximab therapy. N Engl J Med 2001;344:1099-100.

3 Glück T, Linde H-J, Schölmerich J, Müller-Ladner U, Fiehn C, Bohland P. Antitumor necrosis factor therapy and Listeria momocytogenes infection: report of two cases. Arthritis Rheum 2002;46:2255-7.

4 Lee J-H, Slifman NR, Gershon SK, Edwards ET, Schwieterman WD, Siegel JN, et al. Life-threatening histoplasmosis complicating immunotherapy with tumor nercrosis factor $\alpha$ antagonists infliximab and etanercept. Arthritis Rheum 2002;46:2565-70

5 Braun J, Brandt J, Listing J, Zink A, Alten R, Golder W, et al. Treatment of active ankylosing spondylitis with infliximab: a randomised controlled multicenter trial. Lancet 2002;359:1187-93.

6 Mease PJ, Goffe BS, Metz J, Vanderstoep A. Etanercept in the treatment of psoriatic arthritis and psoriasis: a randomised trial. Lancet 2000;356:385-90.

7 Brandt J, Haibel H, Reddig J, Sieper J, Braun J. Successful short term treatment of severe undifferentiated spondyloarthropathy with the anti-tumor necrosis factor- monoclonal antibody infliximab. J Rheumatol 2002;29:118-22.

8 Verduin CM, Hol C, Fleer A, van Dijk H, Van Belkum A. Moraxella catarrhalis: from emerging to established pathogen. Clin Microbiol Rev 2002;15:125-44.

Craig DB, Wehrle PA. Branhamella catarrhalis septic arthritis. J Rheumatol 1983; 10:985-6

10 Izraeli S, Flasterstein B, Shamir R, Rachmel A, Nitzan M, Drucker M, et al. Branhamella catarrhalis as a cause of suppurative arthritis. Pediatr Infect Dis $J$ 1989;8:256-7

\section{Lack of association between angiotensin converting enzyme gene polymorphism and Korean Behçet's disease}

\section{H K Chang, J U Kim, S S Lee, D H Yoo}

$\mathrm{T}$ he histological hallmark of Behçet's disease (BD) is a vasculitis, and endothelial dysfunction has a role in the development of the vascular lesions in $\mathrm{BD} .{ }^{12}$ Angiotensin converting enzyme (ACE) plays a part in the reninangiotensin and kallikrein-kininogen systems by producing angiotensin II from angiotensin I and by inactivating bradykinin. The ACE gene is located on the long arm of chromosome 17, and insertion and deletion (I/D) polymorphism of this gene is strongly related to the levels of circulating ACE: the serum levels of ACE in the DD genotype, homozygote for the deletion allele, are about twice as high as those in the II genotype, homozygote for the insertion allele. ${ }^{3}$ In addition, the DD genotype is associated with endothelial dysfunction, as the stimulated endothelial or donated nitric oxide response is blunted. ${ }^{4}$ Moreover, angiotensin II may participate in the vascular pathogenesis of several diseases through vascular smooth muscle cell contraction and proliferation, monocyte adhesion, and platelet aggregation. However, to our knowledge, there have been no studies on the relationship between the ACE gene and BD. Thus, we studied the potential association between ACE I/D gene polymorphism and Korean BD.

\section{PATIENTS, METHODS, AND RESULTS}

The study group included 70 patients with BD (27 men and 43 women; mean (SD) age 38.1 (7.8)) fulfilling the international study group criteria ${ }^{5}$ and 106 healthy controls (37 men and 69 women; mean (SD) age 37 (11.5)). All the subjects were ethnically homogenous Koreans, unrelated to each other. The cumulative history of severe manifestations was investigated during the disease course, as described in our previous study. ${ }^{6}$ Informed consent was obtained from all the subjects.

ACE I/D polymorphism was determined by polymerase chain reaction genotyping. ${ }^{7}$ The statistical significance was evaluated using $\chi^{2}$ test, $t$ test, or one way analysis of variance test. Values of $\mathrm{p}<0.05$ were considered significant, and these were corrected by multiplying the values by the number of alleles in certain cases.

Table 1 shows that the distribution of genotypes and alleles of the ACE gene did not differ significantly between patients with $\mathrm{BD}$ and controls $(\mathrm{p}>0.05)$, and it was in Hardy-Weinberg equilibrium. In a comparison of clinical variables including sex, clinical manifestations, severe manifestations, and positivity of HLA-B51, no 
Table 1 The distribution of angiotensin converting enzyme genotypes and alleles in the patients with $\mathrm{BD}$ and controls

\begin{tabular}{|c|c|c|c|c|c|}
\hline & \multirow[b]{2}{*}{ No } & \multicolumn{3}{|l|}{ Genotype } & \multirow{2}{*}{$\frac{\text { Allele }}{\text { D v I }}$} \\
\hline & & DD & ID & II & \\
\hline \multicolumn{6}{|l|}{ For study groups } \\
\hline Patients with BD & 70 & $17(24 \%)$ & $28(40 \%)$ & $25(36 \%)$ & $0.44: 0.56$ \\
\hline Controls & 106 & $20(19 \%)$ & $44(42 \%)$ & $42(40 \%)$ & $0.40: 0.60$ \\
\hline \multicolumn{6}{|l|}{ For patients with $B D$} \\
\hline Male (female) & $27(43)$ & $9(8)$ & $12(16)$ & $6(19)$ & $0.56: 0.44(0.37: 0.73)$ \\
\hline Genial ulcerations & $61(9)$ & $13(4)$ & $26(2)$ & $22(3)$ & $0.43: 0.57(0.56: 0.44)$ \\
\hline Skin lesions & $65(5)$ & $15(2)$ & $26(2)$ & $24(1)$ & $0.43: 0.57(0.60: 0.40)$ \\
\hline Ocular lesions & $20(50)$ & $5(12)$ & $6(22)$ & $9(16)$ & $0.40: 0.60(0.46: 0.54)$ \\
\hline Positive pathergy test & $24(46)$ & $4(13)$ & $10(18)$ & $10(15)$ & $0.37: 0.63(0.48: 0.52)$ \\
\hline Intestinal lesions & $16(54)$ & $2(15)$ & 9 (19) & $5(20)$ & $0.41: 0.59(0.45: 0.55)$ \\
\hline Peripheral arthritis & $16(54)$ & $6(11)$ & $6(22)$ & $4(21)$ & $0.56: 0.44(0.41: 0.59)$ \\
\hline Vascular lesions & 11 (59) & $2(15)$ & $5(23)$ & $4(21)$ & $0.41: 0.59(0.45: 0.55)$ \\
\hline CNS lesions & $7(63)$ & $2(15)$ & $2(26)$ & $3(22)$ & $0.43: 0.57(0.44: 0.56)$ \\
\hline Severe manifestations & $27(43)$ & $5(12)$ & $12(16)$ & 10 (15) & $0.41: 0.59(0.46: 0.54)$ \\
\hline Positivity of HLA-B51 & 37 (33) & $9(8)$ & $13(15)$ & $15(10)$ & $0.42: 0.58(0.47: 0.53)$ \\
\hline
\end{tabular}

The values in parentheses in the data for patients with $\mathrm{BD}$ are for the patients lacking each criterion: there were no significant differences in the comparison of genotype and allele frequencies between any two groups, including patients with $B D v$ controls, male $v$ female patients with $B D$, and patients with $B D$ with criterion $v$ without criterion (all $\mathrm{p}>0.05$ ).

significant associations were found in the frequencies of genotypes and alleles between patients with $\mathrm{BD}$ with and without each criterion (all $\mathrm{p}>0.05$ ). Although the D allele frequency was significantly higher in male patients than in female patients, the significance was lost when multiplying by the number of alleles $(p=0.033$, $\mathrm{p}_{\text {corr }}=0.066$ ).

The mean (SD) ages at onset of patients with $\mathrm{BD}$ in each genotype were 33.3 (8.3) (DD), 33.3 (8.0) (ID), and 32.5 (8.2) years (II), and no differences were seen between groups $(p>0.05)$. In a comparison of patients with BD with and without each genotype (DD, ID, II), frequencies of clinical variables (sex, clinical manifestations, severe manifestations, positivity of HLA-B51, mean age at onset) did not differ significantly (all $\mathrm{p}>0.05$ ) (data not shown).

\section{DISCUSSION}

Genetic susceptibility to BD is affected by multiple genes, such as major histocompatibility complex (MHC) and nonMHC genes. Endothelial nitric oxide synthase (eNOS) gene polymorphisms are noted to be associated with the pathogenesis of various vascular diseases, including coronary artery disease (CAD), myocardial infarction (MI), hypertension, and renal diseases. Recently, we reported that Glu298Asp polymorphism of the eNOS gene was another susceptibility gene for Korean $\mathrm{BD}$ and other rheumatic diseases with vasculitis. ${ }^{8}$

ACE gene polymorphism is also reported to be a risk factor for CAD, MI, hypertension, and renal diseases. Furthermore, the DD ACE genotype is associated with endothelial dysfunction, which is believed to have an important role in the development of the vascular lesions in $\mathrm{BD} .{ }^{24}$ On the other hand, associations between the ACE gene and non-Behçet's rheumatic diseases with vascular involvement have been inconsistently reported. ${ }^{9}{ }^{10}$ We therefore considered that the ACE gene might be another candidate gene for BD. However, we could not detect any significant correlation between BD and ACE gene polymorphism. Because of the well known regional differences in the disease expression of $\mathrm{BD}$, further studies in other ethnic populations will be required.

\section{Authors' affiliations}

H K Chang, Department of Internal Medicine, Dankook University, Cheonan, South Korea

J U Kim, Department of Laboratory Medicine, Ulsan University Kangnung, South Korea

S S Lee, Department of Internal Medicine, Chonnam National University Medical School, Gwangju, South Korea

D H Yoo, Department of Internal Medicine, The Hospital for Rheumatic Diseases, Hanyang University, Seoul, South Korea

This study was supported by the research fund of Dankook University in 2003.

Correspondence to: $\mathrm{Dr} \mathrm{H} \mathrm{K}$ Chang, Division of Rheumatology, Department of Internal Medicine, Dankook University, 16-5 AnseoDong, Cheonan, Chungcheongnamdo, 330-715, South Korea; hanks22@dankook.ac.kr

Accepted 14 June 2003

\section{REFERENCES}

1 Sakane T, Takeno M, Suzuki N, Inaba G. Behçet's disease. N Engl J Med 1999;341:1284-91.

2 Schmitz-Huebner U, Knop J. Evidence for an endothelial cell dysfunction in association with Behçet's disease. Thromb Res 1984;34:277-85.

3 Rigat B, Hubert C, Alhenc-Gelas F, Cambien F, Corvol P, Soubrier F. An insertion/deletion polymorphism in the angiotensin I-converting enzyme gene accounting for half the variance of serum enzyme levels. J Clin Invest 1990;86:1343-6.

4 Butler R, Morris AD, Burchell B, Struthers AD. DD angiotensin-converting enzyme gene polymorphism is associated with endothelial dysfunction in normal humans. Hypertension 1999;33:1 164-8.

5 International Study Group for Behçet's disease. Criteria for diagnosis of Behçet's disease. Lancet 1990;335:1078-80.

6 Chang HK, Cheon KS. The clinical significance of a pathergy reaction in patients with Behçet's disease. J Korean Med Sci 2002;17:371-4.

7 Rigat B, Hubert C, Corvol P, Soubrier F. PCR detection of the insertion/ deletion polymorphism of the human angiotensin converting enzyme gene (DCP1) (dipeptidyl carboxypeptidase 1). Nucleic Acids Res 1992;20:1433.

8 Kim JU, Chang HK, Lee SS, Kim JW, Kim KT, Lee SW, et al. Endothelial nitric oxide synthase gene polymorphisms in Behçet's disease and rheumatic diseases with vasculitis. Ann Rheum Dis 2003;62:1083-7.

9 Uhm WS, Lee HS, Chung YH, Kim TH, Bae SC, Joo KB, et al. Angiotensinconverting enzyme gene polymorphism and vascular manifestations in Korean patients with SLE. Lupus 2002;11:227-33.

10 Takeuchi K, Yamamoto K, Kataoka S, Kakihara T, Tanaka A, Sato S, et al. High incidence of angiotensin I converting enzyme genotype II in Kawasaki disease patients with coronary aneurysm. Eur J Pediatr 1997; 156:266-8. 


\title{
Spontaneous pregnancy in a woman with lupus and thyroiditis despite imminent premature ovarian failure
}

\author{
D Le Thi Huong, A Gompel, B Wechsler, J-C Piette
}

Ann Rheum Dis 2004;63:108-109. doi: 10.1136/ard.2002.003012

W report a case of spontaneous pregnancy in a woman with lupus and clinical and hormonal changes suggesting imminent premature ovarian failure (POF).

\section{CASE REPORT}

A French woman born in 1962 had had Raynaud's phenomenon, photosensitivity, and subacute cutaneous lupus since the age of 15 years, which was treated with hydroxychloroquine. She underwent abortions for unwanted pregnancies in 1986, 1987, and 1988. Various progestin contraceptives were prescribed but rapidly stopped. In 1990 she presented with giant cell thyroiditis with normal thyroxine, thyroid stimulating hormone $6.1 \mathrm{mU} / \mathrm{l}$ (normal $0.1-3.2$ ), and negative antithyroperoxidase and antithyroglobulin antibodies. L-Thyroxine $100 \mu$ g daily was started. In August 1992 endometriosis was discovered.

In February 1997 she complained of polyarthritis and sustained climacteric symptoms. She had regular menses with a short luteal phase. Her mother became menopausal at the age of 50. Follicle stimulating hormone (FSH) was increased (95 U/l) with normal oestradiol and karyotype. She was advised to become pregnant rapidly because of imminent POF. Antinuclear antibodies, anti-dsDNA, anti-extractable nuclear antigen and anticardiolipin were negative, total complement $\left(\mathrm{CH}_{50}\right) 34 \mathrm{U}$ (normal 35-55), $\mathrm{C} 30.66 \mathrm{~g} / \mathrm{l}$ (normal 0.7-1.3), C4 $0.1 \mathrm{~g} / \mathrm{l}$ (normal 0.1-0.3). Antithyroglobulin became positive at $1000 \mathrm{U} / \mathrm{ml}$ (normal <100). Articular symptoms remitted with additional treatment with diclofenac.

In January 1998, FSH was $68 \mathrm{U} / \mathrm{l}$ and oestradiol 10 pg/ml, but cycles were still occasionally ovulatory. In the subsequent months, climacteric symptoms remitted. In October 1998 she became spontaneously pregnant. Pregnancy was uneventful with hydroxychloroquine and L-thyroxine. Caesarean section was indicated at 38 weeks because of abnormal cardiotocography, and she delivered a $2910 \mathrm{~g}$ healthy girl.

\section{DISCUSSION}

Our patient had an intermediate status between cutaneous and systemic lupus erythematosus. She developed imminent POF at the age of 35 , without any other cause of ovarian failure. In particular, she did not take thalidomide. ${ }^{1}$ Menopause is defined by the cessation of menstruation for $\geqslant 12$ months with low oestradiol and high gonadotrophins. Menopause is considered premature when it occurs at $<40$ years. POF is suggested in cases of amenorrhoea of $\geqslant 4$ months and confirmed by persistent FSH levels $>40 \mathrm{U} / \mathrm{l}$ at least twice with a one month interval. Despite regular menses, our patient had clinical symptoms and hormonal changes suggesting imminent POF.

Premature menopause and POF affect $1-2 \%$ of women in the general population. ${ }^{2}$ Although known causes of POF include X chromosome deletions, radiation, chemotherapy, and genetic defects of the gonadotrophin hormones or receptors, one third to one half of cases remain idiopathic.
A significant proportion of patients with apparently idiopathic POF have evidence for an autoimmune aetiology because of positive autoantibodies. ${ }^{3}$ However, confirmation of an autoimmune cause requires an ovarian biopsy. Antiovarian and other self tissue antibodies are present in up to one third of women with POF, but the tests are not well standardised and poorly correlated with ovarian histology. Autoimmune POF may occur as an isolated event, be part of the polyglandular autoimmune syndrome, or associated with other autoimmune diseases. Antibodies directed against the corpus luteum were found to be present in $22 \%$ of women with systemic lupus erythematosus (SLE) aged $<40$ years, ${ }^{4}$ but they did not correlate with age, race, SLE activity, other autoantibodies, and treatment. ${ }^{4}$

Our patient had endometriosis, which is associated with an increased prevalence of various autoantibodies: antinuclear, anti-ribonucleoproteins, anti-smooth muscle, anticardiolipin, and lupus anticoagulant. ${ }^{5}$ Endometriosis is characterised by abnormal aromatase activity in endometrial tissue, which leads to local production of oestrogen, inducing prostaglandin $\mathrm{E}_{2}\left(\mathrm{PGE}_{2}\right)$ formation. $\mathrm{PGE}_{2}$ stimulates aromatase expression and establishes a positive feedback cycle. Endometriosis is associated with a twofold increased risk of SLE. ${ }^{6}$ Oestradiol might cause autoimmune changes by mechanisms which have not been clearly elucidated. Association of endometriosis with $\mathrm{POF}^{7}$ suggests that the primary mechanism is hormonal rather than immune.

POF is characterised by occasional recurrent ovarian activity, which occurs more often than in the natural menopause. Patients with POF still have a $5-10 \%$ chance of conceiving after diagnosis. ${ }^{8}$ Glucocorticoids were tried without documented efficiency in autoimmune POF.' Women with hypergonadotrophic hypogonadism may become able to ovulate when treated with oestrogen alone or in combination with gonadotrophins, and may even conceive after treatment with gonadotrophin releasing hormone analogue and gonadotrophins. ${ }^{10}$ In our patient, it is difficult to ascertain whether diclofenac and hydroxychloroquine favoured the spontaneous pregnancy because POF does not imply definitive sterility. About $80 \%$ of pregnancies after POF resulted in the birth of a healthy child. However, no treatment has been found which efficiently restores fertility in prospective controlled studies.

\section{Authors' affiliations}

D Le Thi Huong, B Wechsler, J-C Piette, Department of Internal Medicine, Groupe Hospitalier Pitié-Salpêtrière, 83 boulevard de I'Hôpital 75651 Paris Cedex 13, France

A Gompel, Department of Gynaecology, Hotel-Dieu de Paris, 1 place du Parvis Notre Dame 75004 Paris, France

Correspondence to: Dr D Le Thi Huong; du.boutin@psl.ap-hop-paris.fr

Accepted 3 March 2003 


\section{REFERENCES}

1 Frances C, El Khoury S, Gompel A, Becherel PA, Chosidow O, Piette JC. Transient secondary amenorrhea in women treated by thalidomide. Eur J Dermatol 2002;12:63-5.

2 Vegetti W, Marozzi A, Manfredini E, Testa G, Alagna F, Nicolosi A, et al. Premature ovarian failure. Mol Cell Endocrinol 2000;161:53-7.

3 Falsetti L, Scalchi S, Villani MT, Bugari G. Premature ovarian failure. Gynecol Endocrinol 1999;13:189-95.

4 Pasoto SG, Viana BST, Mendonca BB, Yoshinari NH, Bonfa H. Anti-corpus luteum antibody: a novel serological marker for ovarian dysfunction in systemic lupus erythematosus? J Rheumatol 1999;26:1087-93.

5 Taylor PV, Maloney MD, Campbell JM, Skerrow SM, Nip MM, Parmar R, et al. Autoreactivity in women with endometriosis. Br J Obstet Gynaecol 1991 :98:680-4.
6 Grimes DA, LeBolt SA, Grimes KR, Wingo PA. Systemic lupus erythematosus and reproductive function: a case-control study. Am J Obstet Gynecol 1985; 153:179-86.

7 Kammerer-Doak DN, Magrina JF, Nemiro JS, Lidner TK. Benign gynecologic conditions associated with a CA-125 level $>1000 \mathrm{U} / \mathrm{mL}$. A case report. J Reprod Med 1996:41:179-82.

8 Van Kasteren YM, Schoemaker J. Premature ovarian failure: a systematic review on therapeutic interventions to restore ovarian function and achieve pregnancy. Hum Reprod Update 1999;5:483-92.

9 Kalantaridou SN, Nelson LM. Premature ovarian failure is not premature menopause. Ann New York Acad Sci 2000:900:393-402.

10 Check JH, Summers D, Nazari A, Choe J. Successful pregnancy following in vitro fertilization-embryo transfer despite imminent ovarian failure. Clin Exp Obstet Gynecol 2000;27:97-9.

\title{
Doppler ultrasound identifies increased resistive indices in $\mathrm{SSc}$
}

\author{
N Bregenzer, O Distler, R Meyringer, J Schölmerich, U Müller-Ladner, G Lock
}

C utaneous lesions in patients with systemic sclerosis (SSc) are characterised by fibrosis as well as by changes in the microvasculature. Various methods, including nailbed capillaroscopy, laser Doppler flow monitoring, thermography, and plethysmography, have been used to evaluate distal digitalvascularisationand toassess themicrovasculardamage. ${ }^{1-4}$ In studies using Doppler flowmetry and iontopheresis, patients with SSc showed reduced vasodilatory reserve of the skin microvasculature in response to ischaemia. ${ }^{5}{ }^{6} \mathrm{~A}$ new colour Doppler ultrasound (DU) technique of the nail bed appears to be able to detect and quantify early vascular damage in patients with connective tissue disease. ${ }^{7}$ However, none of these methods has been generally introduced and accepted in clinical routine.

\section{METHODS}

This study aimed at assessing the digital blood flow of patients with SSc by DU. We compared the resistive indices (RIs) of 14 healthy subjects and 19 patients with SSc. Patients with SSc were classified as affected by limited SSc or diffuse SSc according to the criteria proposed by LeRoy et al. ${ }^{8}$ The measurements were performed with an Ultramark 9 HDI duplex Doppler ultrasound (HDI; Advanced Technology Laboratories) after at least 15 minutes of thermal acclimatisation in our ultrasound laboratory. A $10 \mathrm{mHz}$ probe was used for visualising digital vessels (Doppler filter $100 \mathrm{~Hz}$, minimal flow velocity $10 \mathrm{~cm} / \mathrm{s}$ ). The outcome variable was the RI of the distal palmar arteries (arteriae digitales palmares propriae) of the thumb and the forefinger of the right and left hand (dig I and II). The arteries were identified by colour DU. The Doppler samples were obtained at the distal part of the digital artery, and the RI was determined by analysis of the spectral waveforms (fig 1). The RI was calculated according to the standard formula:

$$
\mathrm{RI}=\left(\text { peak }_{\mathrm{SV}}-\mathrm{end} \mathrm{DV}_{\mathrm{DV}}\right) / \text { peak }_{\mathrm{SV}}
$$

where SV = systolic velocity; DV = diastolic velocity.

The RI of each of the digital arteries was determined in duplicate, and the mean of the resulting eight measurements was used for statistical analysis. Measurements were incomplete in seven patients with SSc, because it was impossible to identify all four digital arteries. In these seven patients we used the available measurements for statistical analysis. Statistical analysis was performed using the MannWhitney rank test.
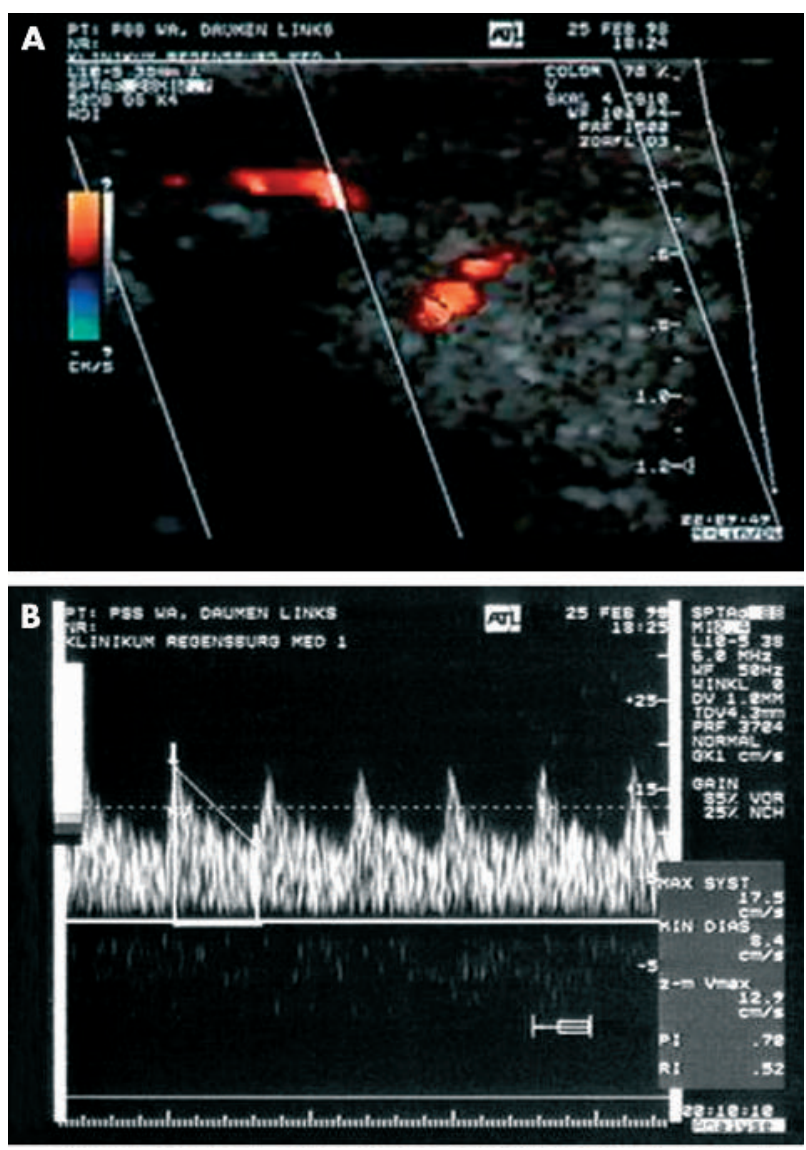

Figure 1 Picture of a colour Doppler ultrasound (A) and the associated spectral waveform (B) of the distal artery of the left thumb (patient with diffuse disease).

\section{RESULTS}

Table 1 shows the clinical characteristics of patients and controls. The mean of all measurements of all fingers showed a significantly higher RI for patients with SSc (limited and diffuse disease $)(R I=0.66)$ than for healthy controls $(\mathrm{RI}=0.59 ; \mathrm{p}=0.01)$. However, there was a considerable overlap between the two groups. Individual digital analysis 


\begin{tabular}{|c|c|c|}
\hline & SSc & Controls \\
\hline Male & 8 & 8 \\
\hline Female & 11 & 6 \\
\hline \multicolumn{3}{|l|}{ Age (mean) years: } \\
\hline Limited disease & $50.3^{*}(p=0.001)$ & 30.9 \\
\hline Diffuse disease & $44.2(p=0.11)$ & \\
\hline Raynaud's phenomenon & 17 & None \\
\hline Unknown & 1 & None \\
\hline Smoking & 1 & 3 \\
\hline Unknown & 1 & None \\
\hline Limited disease & 10 & - \\
\hline Diffuse disease & 9 & - \\
\hline Immunosuppressive drugs & 3 & None \\
\hline Vasodilators & 5 & None \\
\hline
\end{tabular}

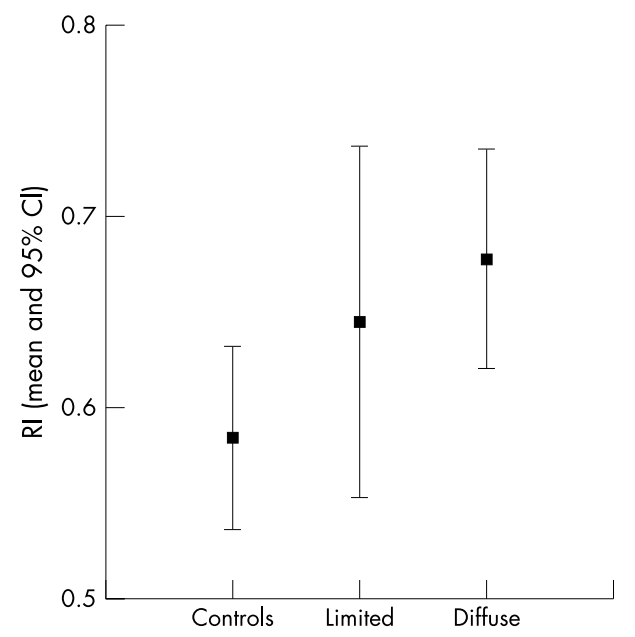

Figure 2 Mean resistive indices and $95 \%$ confidence interval of all measurements of patients with limited disease $(n=10)$, diffuse disease $(n=9)$, and controls $(n=14)$.

showed that the mean of the RI of the left thumb $(p=0.01)$ and the right thumb $(p=0.035)$ were significantly higher in patients with SSc than in normal controls. In contrast, there was no significant difference between the right and left forefinger, and the RI of the individual fingers of the patients did not show a consistent correlation.

We analysed patients with diffuse and limited disease separately, and found no significant difference between healthy controls and patients with limited disease (fig 2). However, patients with diffuse disease showed a significantly higher RI of the left thumb $(p=0.005)$, the right thumb $(p=0.033)$, the left forefinger $(p=0.031)$, the right forefinger $(p=0.046)$, and for the mean of all measurements $(p=0.013)$ in comparison with the healthy controls. In addition, no significant difference between the patients with limited and diffuse disease was found when calculating the mean of all measurements, but in individual digital analysis patients with diffuse disease showed a significantly higher RI of the right forefinger $(p=0.04)$.

In summary DU is an economic and simple non-invasive investigation technique, which may help to provide more information on the status of the digital microvasculature in patients with SSc. The increased RI values may reflect structural changes in digital arterial walls associated with a low vessel compliance, but, owing to the overlap of the RI between both groups, the diagnostic value of the RI measurements in the present group of patients was limited.

\section{Authors' affiliations}

N Bregenzer, O Distler, R Meyringer, J Schölmerich, U Müller-Ladner, G Lock, Department of Internal Medicine I, University of Regensburg, Germany

O Distler, Department of Rheumatology, University Hospital Zürich, Gloriastr. $25 \mathrm{CH}-809$, Zürich, Switzerland

Correspondence to: $\operatorname{Dr} N$ Bregenzer, Department of Internal Medicine I, FJS-Allee 11, University of Regensburg, 93042 Regensburg, Germany; nicole.bregenzer@klinik.uni-regensburg.de

Accepted 26 March 2003

\section{REFERENCES}

1 Cafagna D, Melon F, Balbi M, Ponte E. Vascular manifestations in systemic sclerosis (scleroderma). Minerva Med 1989;89:153-61.

2 La Civita L, Rossi M, Vagheggini G, Storino FA, Credidio L, Pasero G, et al. Microvascular involvement in systemic sclerosis: laser Doppler evaluation of reactivity to acetylcholine and sodium nitroprusside by iontophoresis. Ann Rheum Dis 1998;57:52-5.

3 Stafford L, Englert H, Gover J, Bertouch J. Distribution of macrovascular disease in scleroderma. Ann Rheum Dis 1998:57:476-9.

4 Herrick AL, Clark S. Quantifying digital vascular disease in patients with primary Raynaud's phenomenon and systemic sclerosis. Ann Rheum Dis 1998;57:70-8

5 Wigley FM, Wise RA, Mikdasi J, Schaefer S, Spence RJ. The post-occlusive hyperemic response in patients with systemic sclerosis. Arthritis Rheum 1990;33:1620-5.

6 Goodfiel M, Hume A, Rowell N. Reactive hyperemic responses in systemic sclerosis patients and healthy controls. J Clin Invest Dermatol 1989:93:368-71.

7 Keberle M, Tony HP, Jahns R, Hau M, Haerten R, Jenett M. Assessment of microvascular changes in Raynaud's phenomenon and connective tissue disease using colour doppler ultrasound. Rheumatology (Oxford) 2000:39:1206-13.

8 LeRoy EC, Black C, Fleischmajer R, Jablonska S, Krieg T, Medsger TA, et al. Scleroderma (systemic sclerosis): classification, subsets and pathogenesis. J Rheumatol 1988;15:202-5. 